Dragana M. Đorđević

Filološki fakultet, Beograd ${ }^{* *}$
УДК

811.411.21'276.6:796/799

811.163.41'276.6:796/799

ДОИ

https://doi.org/10.18485/analiff.2016.28.1.12

\title{
ADAPTACIJA POZAJMLJENICA U STANDARDNOM ARAPSKOM JEZIKU
}

Međujezičko pozajmljivanje u arapskom predstavlja jedan od najvažnijih faktora koji su omogućili brzu modernizaciju leksikona arapskog jezika, kao i njegovo proširivanje leksemama i terminima koji označavaju nove pojmove. Analizom primera iz reprezentativnog korpusa arapske sportske terminologije ukazuje se na probleme koji se javljaju prilikom adaptacije pozajmljenica u savremenom standardnom arapskom jeziku uopšte. Akcenat se stavlja na načine na koje se vrši adaptacija glasova bez svog ekvivalenta u arapskom - konsonanata i vokala, adaptacija prema fonotaktičkim zakonitostima arapskog sloga, adaptacija prema arapskim oblicima reči, kao i na ulogu koju u tome imaju asimilacija, elizija, epenteza i proteza glasova. Pošto adaptacija pozajmljenica u standardnom arapskom nije normirana posebnim pravopisnim pravilima ili preporukama, ovim radom se ukazuje i na to do koje mere se adaptacija u praksi ostvaruje na različite načine, što dodatno doprinosi pojavi dubletnih oblika koja znatno opterećuje kako terminosistem sporta, tako i druge terminosisteme i opšti leksikon standardnog arapskog jezika.

Ključne reči: sportska terminologija, savremeni standardni arapski jezik, međujezičko pozajmljivanje, adaptacija, asimilacija, elizija, epenteza, proteza, dublet.

\section{Uvod}

Arapski lingvisti za proces međujezičkog pozajmljivanja koriste termin al-ta 'rīb - ,arabizacija“ koji označava analošku arabizaciju, to jest proces adaptacije kojim se strane reči inkorporiraju u arapski kao jezik-

Filološki fakultet u Beogradu, Katedra za orijentalistiku, Studentski trg 3, 11000 Beograd, Srbija; e-mail: dragana.djordjevic@fil.bg.ac.rs.

** Rad Sportska terminologija kao primer problema adaptacije pozajmljenica u standardnom arapskom jeziku zasniva se delimično na poglavlju 8.2.1 doktorske disertacije pod naslovom Sportska terminologija u standardnom arapskom jeziku odbranjene 21. novembra 2014. na Filološkom fakultetu u Beogradu. 
primalac pri čemu se vrše fonološke i/ili morfološke promene kako bi te reči bile usklađene sa arapskim fonološkim i morfološkim paradigmama (Qinai, 2000: 2; Ali, 1987: 87). To je ujedno i izvorno značenje tog termina, kako su ga koristili arapski jezički stručnjaci još od klasičnog perioda ('Alamī, 2001: 17). ${ }^{1}$ Objektivno posmatrano, međujezičko pozajmljivanje u arapskom predstavlja jedan od najvažnijih faktora koji su omogućili brzu modernizaciju arapskog jezika, iako taj proces nije bio jednoglasno prihvaćen (Stetkevych, 1970: 56). Poredeći klasični i moderni period, el Hafaifi primećuje da su arapski srednjovekovni jezički stručnjaci imali mnogo slobodniji stav prema pozajmljivanju u odnosu na njihove savremene naslednike (Elkhafaifi, 2002: 260). U modernom, kao i u klasičnom periodu, postojali su puristi koji su se protivili uvođenju stranih reči u leksički fond arapskog jezika, ali je većina jezičkih stručnjaka bila spremna da prihvati pozajmljivanje kao legitiman metod proširivanja leksikona pod uslovom da se lekseme ,arabizuju“, to jest adaptiraju arapskoj jezičkoj strukturi na fonetskom i morfološkom planu. Ipak, akademije za arapski jezik su zazuzele tvrđi stav prema kom je pozajmljivanje dopušteno samo u okviru naučnih i stručnih terminologija. Iako su akademije pokušale da postave isto ograničenje i za stvaranje novih izvedenica nastalih iz ovako adaptiranih pozajmljenica, to nije zaživelo u praksi. Svi jezički stručnjaci moderne epohe su bili složni u tome da bi najbolje rešenje bilo da se strane reči, gde god je to moguće, zamene arapskim (Versteegh, 2001: 178-179). Upravo tako nešto tvrdi Sajadi kad kaže da su akademije ,zajedno potvrdile da treba oživeti staro pre nego što se pohita ka izmišljanju novog“" (Ṣayādī, 1985: 74). Mnogi zapadni arabisti, poput Stetkeviča, Holsa, Kica, Parkinsona i donekle Fersteiha, smatraju da je takav stav u potpunosti zasnovan na konzervativnoj filološkoj tradiciji i negativno ga ocenjuju jer je prilično rigidan i preskriptivistički nastrojen, (Stetkevych, 1970: 114-123; Versteegh, 2001: 177-183; Holes, 2004: 309-314; Kico, 2003: 252; Parkinson, 1991: 36).

Iako predstavlja veoma specifičnu ljudsku aktivnost kroz čiju se prizmu neretko prelamaju ekonomske, socijalne i političke dimenzije

1 Arabizacija (ar. al-ta 'rīb) je izrazito višeznačan termin arabističke lingvistike koji se u užem leksikološkom značenju, kao što je slučaj u ovom radu, odnosi na adaptaciju i asimilaciju pozajmljenica. Među ostalim, širim značenjima posebno su važna ona vezana za pitanja jezičkog planiranja u arapskim državama u XX i XXI veku (Đorđević, 2014: 117-119 i 280-281). 
društva i civilizacije, aktivnost koja poseduje vrlo raznovrsne jezičke realizacije, sport nije previše često zastupljen u arabističkim lingvističkim proučavanjima, iako može da pruži značajne uvide u vezi sa terminološkim i drugim aspektima upotrebe arapskog jezika. Navešćemo ovde i stav nemačkog lingviste Tomasa Šmita (Thomas Schmidt) u vezi sa značajem proučavanja jezika fudbala, jer se u potpunosti može primeniti i na proučavanja sportske terminologije i jezika sporta uopšte:

„The language of football offers many rewarding topics for linguistic research. One such topic is the lexicographic analysis of football vocabulary. Since, on the one hand, a football match is made up of a relatively small number of ever-recurring events (shots, passes, referee interventions etc.), but, on the other hand, myriads of texts (written reports, spoken commentary etc.) are produced every day which describe these events, a vocabulary has been developed in many languages which abounds with synonyms, with finegrained semantic distinctions and with subtle stylistic variation" (Schmidt, 2008: 11).

\section{O formalnom aspektu adaptacije stranih reči u arapskom}

Način na koji će jezik usvojiti strani termin i da li će tako usvojeni termin imati svoje derivate zavisi od nekoliko faktora. Među njima se naročito ističu srodnost jezika davaoca $i$ jezika primaoca, sličnost njihovih pisama, sličnost njihovih glasovnih i gramatičkih sistema, pravopisne norme jezika primaoca i tako dalje. U srodnim jezicima, sa sličnim pismima i sličnim fonološkim sistemima, pozajmljenica može da očuva izvorni način pisanja, izgovora i kontekstualne oblike ako to pravopisna norma jezika primaoca dopušta. U nesrodnim jezicima ili jezicima sa različitim grafološkim i fonološkim sistemima, pozajmljenica podleže adaptaciji prilagođavanju na grafološkom, fonološkom, morfološkom, sintaksičkom i semantičkom planu, u skladu sa gramatičkom normom i upotrebnim navikama koje nameće jezik primalac.

Kada je reč o sportskoj terminologiji u savremenom standadnom arapskom jeziku², većina pozajmljenica potiče iz engleskog jezika koji

2 Savremeni standardni ili savremeni književni arapski jezik (eng. Modern Standard Arabic - MSA ili Modern Literary Arabic - MLA) termin je kojim se u lingvističkoj arabistici na Zapadu naziva savremeni potomak klasičnog arapskog jezika. Nastao 
u tom smislu ima dvojaku ulogu: ulogu direktnog izvora termina ili pak posrednika u prenošenju termina iz nekog drugog jezika. Takva uloga engleskog jezika najpre je posledica činjenice da je Engleska kolevka modernog sporta, budući da su u njoj u 19. veku definisana prva pravila modernih sportskih disciplina ${ }^{3}$. Dakle, pozajmljenice $u$ arapskoj sportskoj terminologiji potiču iz jezika sa nesrodnim pismima, na čelu sa engleskim. Muftić ukazuje na to da kod preuzimanja reči iz jezika sa nesrodnim pismom dolazi do prenošenja stranog izgovora slovima arapskog pisma, pri čemu dolazi do manjeg ili većeg prilagođavanja arapskom jeziku (Muftić, 1982: 198).

Što se tiče izgovora pozajmljenica koje sadrže glasove bez svog ekvivalenta u arapskom, a on se neposredno odražava i na beleženje takvih pozajmljenica, varira od izgovora koji je blizak izvornom to jest stranom, do izgovora koji je bliži arapskom. Koliko će izgovor biti blizak izvornom, kako zapaža el Kinai (Jamal al-Qinai), zavisi od dva faktora. To su:

1. nivo obrazovanja govornika - obrazovani korisnici takvih reči često imaju sklonost da reprodukuju ili oponašaju izvorne (strane) glasove, naročito ako znaju strani jezik koji je u pitanju;

2. uticaj dijalekata - u izvesnim dijalektima arapskog jezika usvaja se izvorni (dijalekatski) izgovor pozajmljenica (Qinai, 2000: 11).

To se zapažanje u sportskoj terminologiji u savremenom standardnom arapskom jeziku može potvrditi sledećim primerima iz sportske terminologije ${ }^{4}$ :

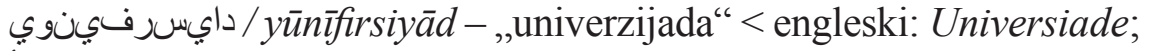

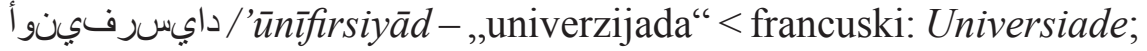

je u XIX veku i predstavlja ,unifikovan i kodifikovan panarapski varijetet“ koji se koristi za „sve vidove pisanja u arapskom svetu, a danas, u svom govorenom obliku, dominira radio-talasima i televizijskim kanalima u svakoj arapskoj zemlji“ (Holes, 2004: 5).

3 Više informacija o istoriji i razvoju međunarodnog i arapskog sporta nudi drugo poglavlje teze Sportska terminologija u standardnom arapskom jeziku (Đorđević, 2014: 3-40).

$4 \quad$ U radu je korišćen korpus sportske terminologije u standardnom arapskom jeziku koji je bio deo disertacije na kojoj se rad i zasniva (Đorđević, 2014: 169-240) i sastoji se od ukupno 1983 arapska termina iz različitih oblasti sporta. Primeri su beleženi arapskim pismom i ZDMG transkripcijom. 
/ ودوج / ودوج

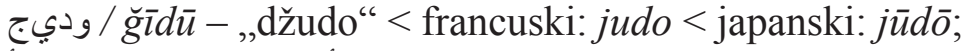

أ / ' 'ufsāyd - ,ofsajd“ > engleski: offside;

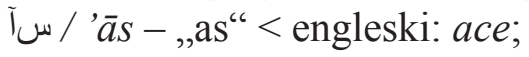

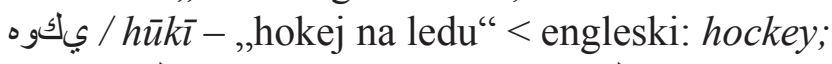

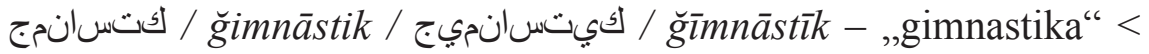
engleski: gymnastics < starogrčki: gymnastike;

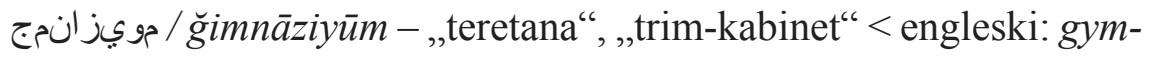
nasium.

Kako se vidi iz pojedinih primera, što će i u narednoj analizi biti potvrđeno, prilikom adaptacije javljaju se dubletni oblici koji su posledica različitih načina adaptacije direktnih pozajmljenica bilo da je reč o adaptaciji vokala ili konsonanata.

Kada je reč o formalnom aspektu adaptacije stranih reči u arapskom, ugledni jugoslovenski arabista Srđan Janković zapazio je sledeće:

„Svaka strana riječ koja se preuzima u arapski jezik nužno je podvrgnuta procesu adaptiranja prema uzusima arapskog jezika. Adaptacija se očituje, prije svega, na fonetskom planu, gdje posebno dolaze do izražaja djelovanje ne samo arapskog fonološkog sistema nego i njegovih fonotaktičkih zakonitosti.

U tom smislu adaptaciju stranih riječi u arapskom možemo pratiti u tri posebna vida: 1. adaptiranje glasova koji nemaju ekvivalenta u arapskom, 2. adaptiranje prema fonotaktičkim zakonitostima arapskog sloga i 3. adaptiranje prema arapskim oblicima riječi““ (Janković, 1987: 127).

Takav pristup adaptaciji primenićemo i u ovom radu, pri čemu ćemo se baviti problemima prilagođavanja pozajmljenica na grafološkom, fonološkom i morfološkom planu u savremenom standardnom arapskom jeziku.

\section{Adaptiranje konsonanata koji nemaju svog ekvivalenta $u$ arapskom}

Dok su strani glasovi koji su fonetski bliski određenim arapskim glasovima jednostavni za prenošenje, adaptiranje glasova koji nemaju svoje ekvivalente u arapskom se najčešće vrši ,na osnovu najbližeg fonetskog ekvivalenta" (Janković, 1987: 128), odnosno takvi glasovi se zamenjuju najbližim homorganskim ekvivalentima (Qinai, 2000: 8). El Kinai ukazuje 
na to da kod jednog broja arapskih jezičkih stručnjaka postoji nedoumica u vezi sa pitanjem da li adaptaciju stranih reči regulišu stroga analoška pravila ili je sankcioniše svakodnevna upotreba. Ta nedoumica je posledica činjenice da u srednjem veku nisu postojala čvrsta pravila u vezi sa adaptacijom stranih reči, već su oni koji su bavili adaptacijom, uglavnom prevodioci tekstova sa stranih jezika, činili to nedosledno, primenjujući pravila klasičnog arapskog jezika na lekseme koje su nastale prema pravilima izvornog jezika (Qinai, 2000: 2).

Iako pozajmljenice i ad hoc traskripcije stranih reči koriste iste opšte principe ortografskog prilagođavanja, one ,često iskazuju regionalne varijacije koje su odraz lokalne fonologije“ (Badawi et al., 2007: 17). Pri tome se neki od tih konsonanata koji nemaju svoje ekvivalente u arapskom beleže na sledeći način: $c \rightarrow$ ا

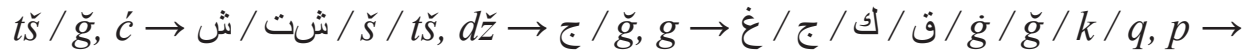

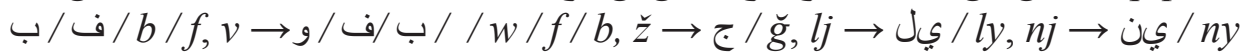
(Janković, 1987: 128-129; Muftić, 1982: 209; Muftić, 1998: 82; Badawi et al., 2007: 17; Qinai, 2000: 8-10). U vezi sa beleženjem stranih suglasnika Muftić uočava da se ne primenjuje fonetski princip, gde bi svaki glas bio označen po jednim slovom, iako predstavlja osnovni princip arapskog pravopisa (Muftić, 1982: 209).

$\mathrm{U}$ arapskoj sportskoj terminologiji nalazimo sledeće primere za beleženje konsonanata koji ne postoje u arapskom:

$$
\begin{aligned}
& \circ p \rightarrow \varphi / b: \\
& \text { / trāmbūlīn - ,trambulina“ > engleski: trampoline - } \\
& \text { „trambulina“; }
\end{aligned}
$$

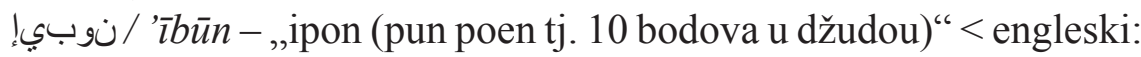

$$
\begin{aligned}
& \text { ippon < japanski: ippon; } \\
& \text { (kābtin - ,kapiten“ > engleski: team captain; } \\
& \text { أنìtāis - ,pilates“ > engleski: pilates; } \\
& \text { الكساف اتولبي / bìlūta (vāskā) - ,baskijska pelota“ > baskijski: } \\
& \text { pelota vasca; } \\
& \text { / bintātlūn - ,petoboj“, ,ppentatlon“ > engleski: pentath- } \\
& \text { ا توشار اب / bārāāšut - ,padobran“ > engleski: parachute; }
\end{aligned}
$$




\footnotetext{
/كرتيجويلب / blāyūmītrik(s) / سكرتيجوي /

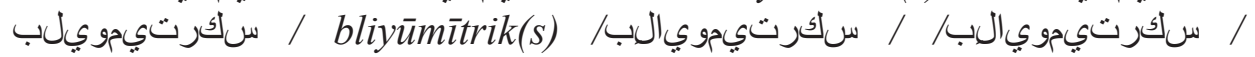

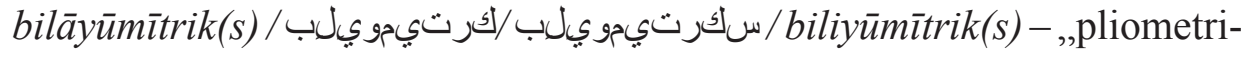
ja“" < engleski: plyometrics.
}

Kod poslednjeg primera za termin pliometrija primećujemo da postoje dubletni oblici i očigledna nedoslednost prilikom njene adaptacije. To je posledica beleženja različitih izgovora datog termina prilikom adaptacije.

Janković ističe da se kod poznavalaca izvornih jezika neguje izvorni izgovor, pa se u grafiji mogu pojaviti i marginalne grafeme za $p$ i $b$ (Janković, 1987: 128), to jest $»$.

$$
\circ v \rightarrow \omega / f:
$$

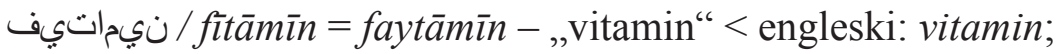

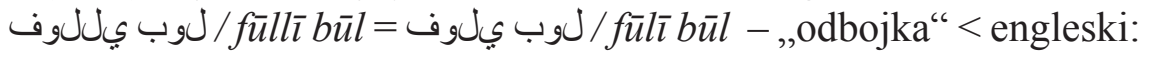
volleyball.

$$
\text { og } \rightarrow \dot{\varepsilon} / \text { / / / / } / \dot{g} / \breve{g} / k / q:
$$

Jedna od izraženih karakteristika adaptiranja stranih glasova koji nemaju svoje ekvivalente $\mathrm{u}$ arapskom jeste različito preuzimanje konsonanta $g$, a to je uslovljeno geografsko-dijalekatskim razlikama. Adaptiranje $g \rightarrow$ ج / $\breve{g}$ javlja se u sferi egipatskog kulturnog uticaja, $g \rightarrow 5 / k$, koje je znatno ređe, karakteristično je za oblast Iraka, dok je adaptiranje $g \rightarrow \dot{\varepsilon} / \dot{g}$ karakteristično za sve ostale oblasti (Janković, 1987: 128-129). Adaptiranje $g \rightarrow$ ق $/ q$ je najređe i rečnici sportske terminologije zvaničnih institucija ga ne beleže, iako je takav način adaptiranja zabeležen u praksi. Možemo pretpostaviti da je takvo adaptiranje nastalo pod uticajem takozvanih nomadskih dijalekata u kojima se $q \bar{a} f$ izgovara kao $g \bar{a} f$, a koji su najpre rasprostranjeni u većem delu severa Afrike (Bateson, 1967: 101). Na primer:

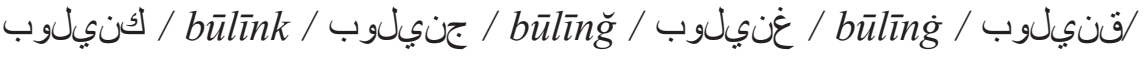
būlinnq - ,kuglanje“ < engleski: bowling; 


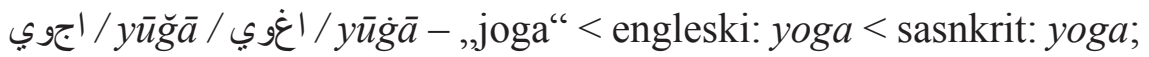

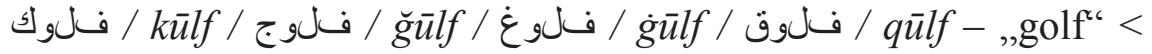
engleski: golf;

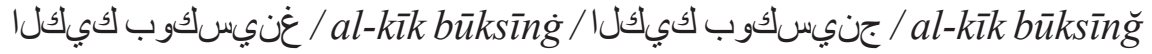
- al-kīk büksinnq „,kik-boks" < engleski: kick boxing;

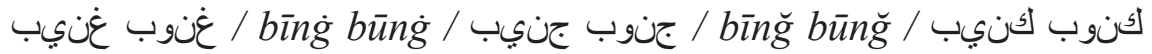
/ bink būnk / قنوب قنبي / binnq bünq - ,stoni tenis“, ,ping-pong“ > engleski: ping-pong (robna marka opreme za stoni tenis registrovana 1900. godine u Americi i sinonim za stoni tenis);

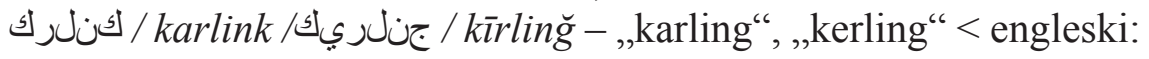
curling.

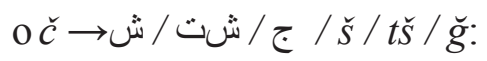

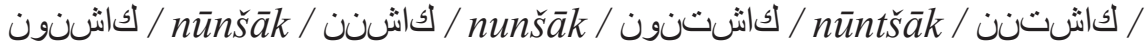
nuntšāk - ,nunčake“ < engleski: nunchuks/nunchuk/nunchaku < japanski: nunchaku;

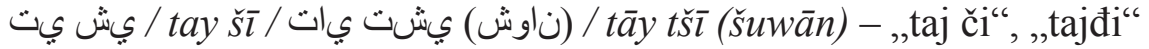
$<$ engleski: Tai chi chuan < kineski: tàijíquán.

Iako je to srazmerno retko, u građi nalazimo i primer da se konsonant $\check{c}$ može preneti i arapskim konsonantom $\breve{g}$. Na primer:

banš bris - „benč-pres“ < engleski: bench press;

( dikka al-banğ - ,benč (vrsta klupe u teretani)“, doslovno: „klupa benč“, „klupa klupa“ < engleski: bench.

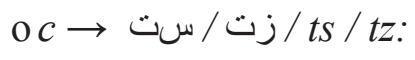

أكون / liutz - ,luc (figura u umetničkom klizanju)“ < nemački: lutz;

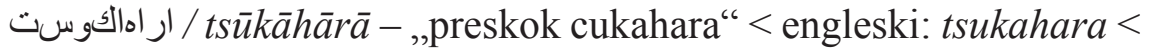
japanski: tsukahara; jūjutsu.

/ وسبج / وسوج 
U proučavanom korpusu sportske terminologije nije zabeleženo korišćenje grafeme $j / z$ kao ekvivalenta glasa $c$.

$\mathrm{o} \check{z} \rightarrow$ ج $/ \breve{g}:$

( قتكاج / ğākita - ,jakna“, ,prsluk“ > engleski: jacket/ italijanski: giachetta;

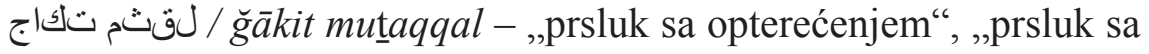
tegovima" < engleski: weight jacket/weight vest.

Da se pravilo adaptiranja na osnovu najbližeg fonetskog ekvivalenta u praksi prilično nedosledno primenjuje potvrđuje i ne previše raširena ali prisutna pojava stavljanja dodatnih dijakritičkih tačaka na arapska slova sličnog izgovora: $g \rightarrow \dot{\varepsilon}, v \rightarrow ث, p \rightarrow \Psi, \check{z} \rightarrow$ (Muftić, 1998: 82; Badawi et al., 2007: 17), koja je zabeležena u korišćenom korpusu sportske terminologije samo u jednom slučaju, kod prenošenja naziva baskijske pelote -

Badavi (Elsaid Badawi) i drugi koautori opsežne gramatike Modern Written Arabic: A Comprehensive Grammar, tvrde da se nove grafeme, sa dodatnim dijakritičkim tačkama, javljaju samo kod pozajmljenica novijeg datuma. Oni uočavaju i da se ponekad umesto simbola šadda, kojim se označava podvostručeni glas, koriste podvostručene grafeme (Badawi et al., 2007: 17). Takva pojava se, doduše retko, zapaža i u sportskoj terminologiji standardnog arapskog jezika. Na primer:

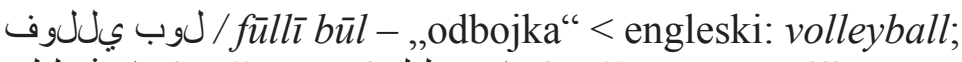

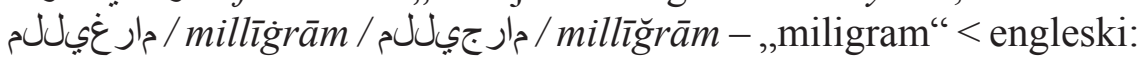
milligram / francuski: milligrame.

U savremenom standardnom arapskom jeziku ponekad se primenjuje i praksa navođenja originalne grafije uz transkribovanu pozajmljenicu ili se čak takva grafija koristi sama, što može da omogući poznavaocu određenog stranog jezika da ispravno izgovori transkribovanu pozajmljenicu, ili da jednostavno pruži uvid u autentičnu grafiju i izgovor adaptiranog termina. Muftić ukazuje na to da se to se najčešće čini u slučaju kada pozajmljenica potiče iz jezika sa prepoznatljivim pismom, ili korišćenjem neke međunarodne transkripcije ako pozajmljenica potiče iz jezika sa 
manje prepoznatljivim pismom (Muftić, 1998: 82). Za navođenje originalne grafije uz arapski termin postoji još nekoliko razloga koji se neretko međusobno prepliću. Pored već navedenog, to su: neustaljenost termina, ili uvođenje novog termina, postojanje više termina u datom terminosistemu koji upućuju na isti pojam, kao i potreba da se izvrši dodatno preciziranje pojma na koji dati termin upućuje. Originalna grafija se može navoditi uz adaptiranu pozajmljenicu, ali i uz prevedenicu. Na primer:

شاوكس (al- 'iskwā̌s ) / squash - ,,skvoš““;

(al-būlü) / polo - ,polo“;

(al-ğŭğ̄ riyū) / goju ryo - ,godžu-rju (škola/stil u modernom karateu)";

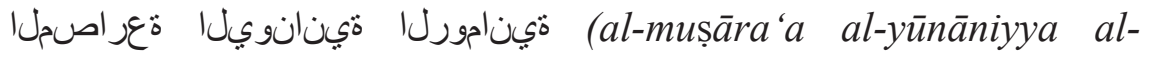
rūmāniyya) / Graeco-Roman wrestling - ,rvanje grčko-rimskim stilom“;

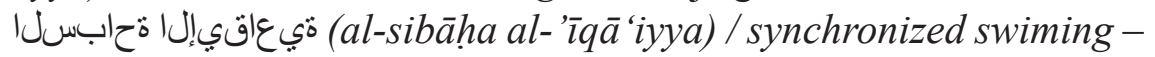
„,sinhrono plivanje“, ,umetničko plivanje“.

Uvidom u relevantnu građu, utvrdili smo i to da je moguća pojava samog stranog termina u izvornoj grafiji sa dodavanjem određenih arapskih elemenata, kao što je određeni član, ili sa smeštanjem stranog termina u okvire arapske konstrukcije. Ta pojava zabeležena je samo u okviru tekstualnih realizacija arapskog sportskog naučnog funkcionalnog stila. Na primer:

DI」 (al-D) - „D (polukružni oblik u bilijaru i snukeru koji zatvara prava linija (tzv. baulk-linija) prečnika od $292 \mathrm{~mm}$ )“ < engleski: the D;

ةقيرط WM (tarīqa WM) - ,formacija WM“ < engleski: WM formation - „formacija koja, gledano iz vazduha, ima oblik latiničnih slova WM“;

ققيرط $M M($ tarīqa $M M)$ - ,,formacija čovek-na-čoveka“ < engleski: MM formation / man-to-man formation.

\section{Adaptiranje vokala}

Što se tiče adaptiranja vokala, ono je prilično neujednačeno u arapskom pravopisu (Muftić, 1998: 81), iako tu važi isto opšte pravilo kao i za konsonante - vrši se na osnovu najbližeg fonetskog ekvivalenta. Vo- 
kali na početku reči se obeležavaju pomoću hamze (') na nosiocu alifu i odgovarajućih kratkih $(a, i, u)$ ili dugih vokala $(\bar{a}, \bar{l}, \bar{u})$ koji određuju položaj hamze u skladu sa pravilima gramatike arapskog jezika. U sredini se koriste arapski $\operatorname{kratki}(a, i, u)$ ili dugi vokali $(\bar{a}, \bar{l}, \bar{u})$, a na kraju se koriste odgovarajuća slova kojima se označavaju dugi vokali u arapskom $(\bar{a}, \bar{l}$, $\bar{u})$ ili, ponekad, vokalno-konsonantski nastavci $a h$ ili mocioni sufiks $-a t^{u n}$, da označe vokale $a$ ili $e$. Iako je primetna tendencija da se svi vokali, bez obzira na to da li su kratki ili dugi, prenose slovima kojima se označavaju dugi vokali u arapskom, i tu postoje izvesna kolebanja pa se javljaju i dubletni oblici (Janković, 1987: 129-130; Badawi et al., 2007: 18; Muftić, 1998: 81-82; Muftić, 1982: 208-209). Stoga Muftić s pravom naglašava da se u transkripciji stranih samoglasnika javlja „očita nedosljednost pri obeležavanju ne samo kvantiteta, nego i kvaliteta tih vokala normalnim sredstvima arapskog pisma“" (Muftić, 1998: 82).

U sportskoj terminologiji u arapskom jeziku, vokali na početku reči u arapskom se adaptiraju na sledeći način:

o $o / \bar{o} / u / \bar{u}: \rightarrow$ و وأl'u/'ü:

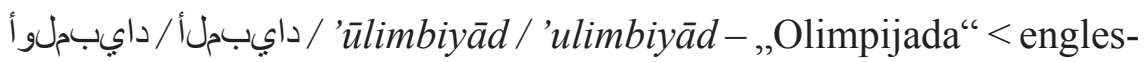
ki: Olympics;

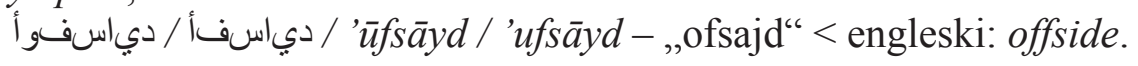$$
\text { o } e / \bar{e} / i / \bar{\imath} \rightarrow ! / l_{1}-{ }^{\prime} i /{ }^{\prime} \bar{\imath}:
$$

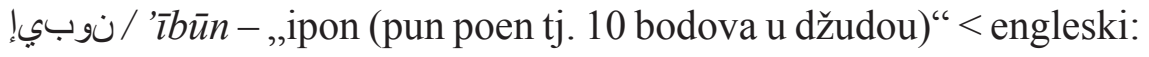
ippon $<$ japanski: ippon.

$$
\text { o } a / \bar{a} \rightarrow \mathrm{I} / \mathrm{i} /{ }^{\prime} a / ' \bar{a}:
$$

أ / 'antrūbūmitriyy - ,,antropometrički“" > engleski: anthropometric;

سآ / ' 'âs - ,as (vrsta servisa u tenisu)“" < engleski: ace.

Vokali u sredini reči se u sportskoj terminologiji u arapskom adaptiraju na sledeći način: 
o $o / \bar{o} / u / \bar{u} \rightarrow-' / g / u / \bar{u}:$

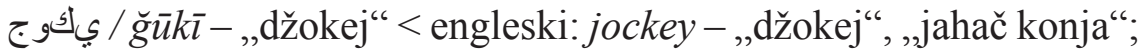

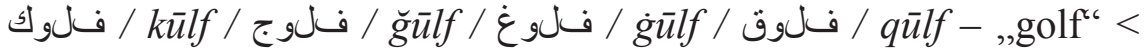
engleski: golf;

/ ودوج / ودو

ا لوب تففوس süft bül - ,softbol““ engleski: softball.

o $e / \bar{e} / i / \bar{\imath} \rightarrow-/ . /$ - $/ i / \bar{\imath}:$

/كرتيمويلب / blāyūmītrik(s) / سكرتيمويالب / كرتيمويالب

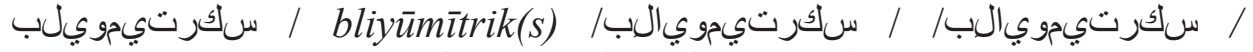

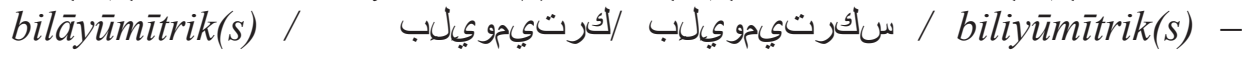
„pliometrija“ < engleski: plyometrics;

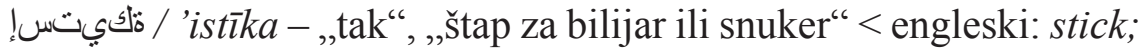

( سنت / tinis - „tenis“ > engleski: tennis;

/ simin kūntākt - ,semi kontakt" > engleski: semi contact.

o otvoreno $e / a / \bar{a} \rightarrow-\prime / l / a / \bar{a}$ :

kīnāmātīkiyy - ,kinematički“ > engleski: kinematic;

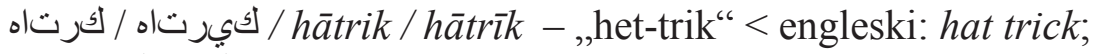
chanics;

年 / biyūmīkānīkā - ,biomehanika“ < engleski: biome-

baň́ bris - „benč-pres“ < engleski: bench press;

شات / mātš - „mečc“ < engleski: match.

Ipak, kod oblika kīnāmātīkiyy - ,kinematički“ javlja se i dubletni oblik koji ukazuje na pomenutu nedoslednost u beleženju vokala kod pozajmljenica istog porekla:

. kinīmātīkiyy - ,kinematički“ > engleski: kinematic.

Tendencija da se svi vokali, kratki i dugi, prenose slovima kojima se označavaju dugi vokali u arapskom, prema Jankovićevom mišljenju predstavlja grafijsko markiranje strane forme, koje u isto vreme protivureči 
jednom od osnovnih grafijskih pravila arapskog jezika - da se na taj način obeležavaju samo dugi vokali. Zbog toga postoje izvesna kolebanja u takvom načinu pisanja pa se i tu neretko javljaju grafijski dubleti (Janković, 1987: 129). Na primer:

$$
\text { / رتمونام /رتيجونام /mānūmītr = mānūmitr - ,manometar“ < engles- }
$$

ki: manometer;

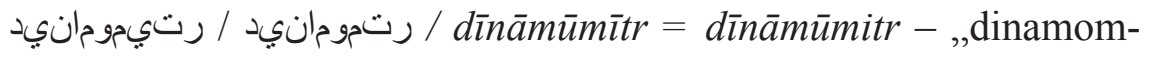
etar" < engleski: dynamometer;

أ / 'antrūbūmìtriyy = 'antrūbūmitriyy - ,antropometrički“ < engleski: anthropometric;

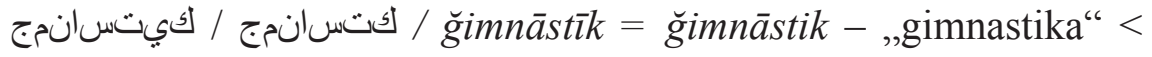
engleski: gymnastics.

Vokali na kraju reči se u sportskoj terminologiji u arapskom jeziku adaptiraju na sledeći način:

o $a / \bar{a} \rightarrow 1 / \circ / \ddot{o} / \bar{a} /-a h /-a t^{u n}$ :

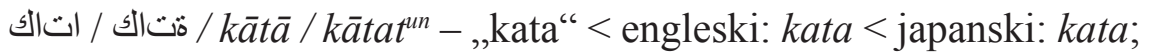
/ مكين|اكيمويب / biyūmīkānīkā / biyūmīkānīkat"un / biyūmīkānīkah - ,biomehanika“ < engleski: biomechanics.

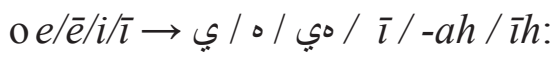

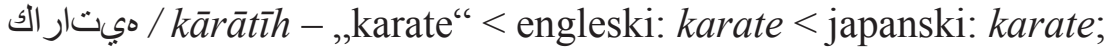

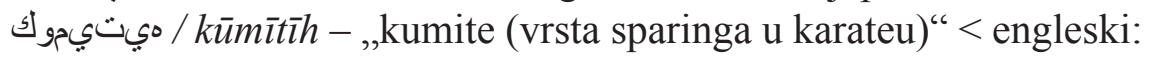
kumite < japanski: kumite;

ميل / bālīh - ,balet“ > engleski/francuski: ballet;

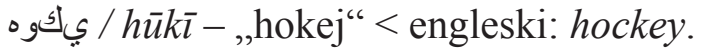

o $o / u / \bar{o} / \bar{u} \rightarrow g /$ go / $\bar{u} / \bar{u} h:$

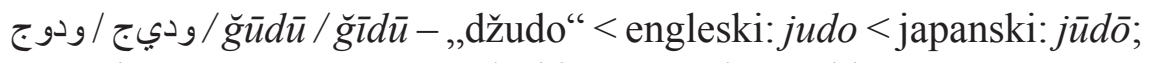
/ وموس / sūmū - ,Sumo“ > engleski: sumo < japanski: sumō;

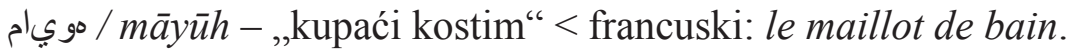




\section{Adaptiranje prema fonotaktičkim zakonitostima arapskog sloga}

Najveći uticaj fonotaktičkih zakonitosti arapskog sloga ogleda se kod prenošenja suglasničkih grupa na početku reči. One moraju da budu eliminisane jer arapski slog u standardnom jeziku ne može da počne sa dva suglasnika. Eliminacija početne grupe od dva suglasnika u preuzetoj stranoj reči postiže se na tri načina. To su epenteza ili umetanje pomoćnog vokala između dva konsonanta, proteza ili stavljanje protetičkog pomoćnog vokala ispred početne suglasničke grupe i eliminacija, tj. otpadanje jednog suglasnika iz te suglasničke grupe, što je najređi slučaj (Janković, 1987: 130-131; Qinai, 2000: 14-15).

U sportskoj terminologiji u standardnom arapskom jeziku javljaju se sva tri načina, premda su epenteza i proteza mnogo rasprostranjenije od eliminacije konsonanta.

Epenteza ili umetanje pomoćnog vokala između dva konsonanta za rezultat ima stvaranje dva sloga. Na primer:

/ blāyūmītrik / blāyūmītriks /

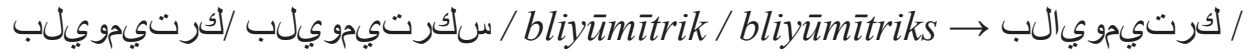

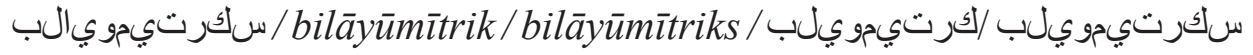
/ biliyūmìtrik / biliyūmītriks - ,pliometrija“ < engleski: plyometrics;

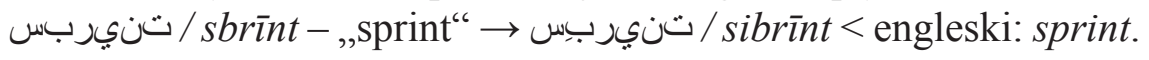

Kako primeri iz arapske sportske terminologije ukazuju, za epentezu u standardnom arapskom jeziku karakteristično je umetanje isključivo kratkih vokala, koji se retko kada pišu, tako da se epenteza praktično primenjuje samo u govoru.

Proteza ili stavljanje protetičkog pomoćnog vokala ispred početne suglasničke grupe postiže se pomoću konsonanta hamze i vokala, najčešće kratkog $i$, pri čemu takođe nastaju dva sloga. Na primer:

إ / 'istād - ,stadion“ > francuski: stade > starogrčki: stadion;

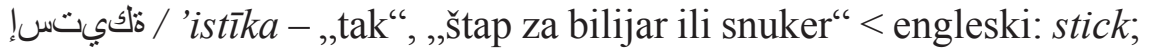

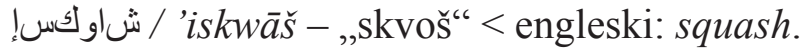

Eliminacija ili uklanjanje jednog suglasnika iz početne suglasničke grupe predstavlja retku pojavu. Jedini pronađeni primer za ovu pojavu u 
sportskoj terminologiji u arapskom jeziku je pomalo neobičan, jer u reči dolazi do uklanjanja hamze kao početnog konsonanta i dodavanja kratkog protetičkog vokala:

$$
\text { kurūbātīkiyy - ,akrobatski“ > engleski: acrobatic. }
$$

\section{Adaptiranje prema arapskim oblicima reči}

Prilikom preuzimanja stranih reči u arapskom, neretko dolazi do njihovog adaptiranja prema arapskim ,paradigmama za klase riječi““ (Janković, 1987: 131), to jest do prilagođavanja njihovog oblika arapskim rečima. Takva vrsta adaptacije može da se izvede bez ikakve intervencije, kod stranih reči koje se oblički uklapaju u morfologiju arapskog jezika. Ipak, najčešće zahteva manje intervencije, kao što su dodavanje dugih vokala i/ili nekih nastavaka. U okviru ove vrste adaptacije najčešće se koriste arapske paradigme za glagolsku imenicu I vrste ( $f$ ' $l, f a ' l$ i tome slično), glagolske imenice II vrste $\left(\operatorname{taf}^{\prime} \bar{\imath} l\right)$, glagolske imenice III vrste (mufā'ala) i participa aktivnog I vrste $(f \bar{a} ' i l)$. U sportskoj terminologiji u arapskom jeziku nalazimo sledeće primere za ovu pojavu:

مروانم / munāwara - ,manevar“ > oblik glagolske imenice III vrste mufā 'ala < turski: manovara < francuski: manœuvre;

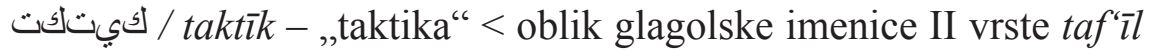
< engleski: tactics/francuski: tactique - „taktika“;

(كينكت / taknīk - ,tehnika““ > oblik glagolske imenice II vrste taf'īl < francuski: technique/engleski: technique - „tehnika“;

/ taqniyya - ,tehnika“ > oblik glagolske imenice II vrste taf'īl < francuski: technique/engleski: technique - „tehnika“;

(بâbir - ,sablja“ < oblik participa aktivnog I vrste fā'il < engleski: saber.

Adaptiranje prema arapskim oblicima reči može i da obuhvati građenje četvororadikalnih oblika od svih ili pojedinih konsonanata koji se nalaze u osnovi izvorne reči. Pri tome izvorni termin može biti podvrgnut različitim fonetskim promenama. Na primer:

/ لبند / danbal - „bućica (vrsta tega)“ > engleski: dumbbells;

/ ثلجرف / farmala - ,kočnica“ > italijanski: freno - ,kočnica“; 
bling.
/ dلبرد / darbala - ,driblanje“, ,dribling“ < engleski: dribble, drib-

Tako adaptirani termini mogu do te mere da se uklope u pravila arapskog jezika da često iskazuju sposobnost građenja slomljenog (unutrašnjeg) plurala (Beeston, 1970: 33). Na primer:

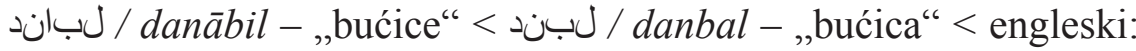
dumbbells;

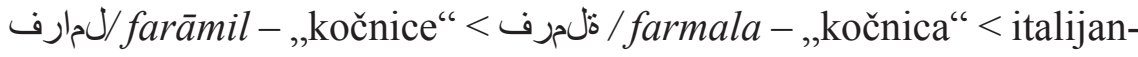
ski: freno - „kočnica“;

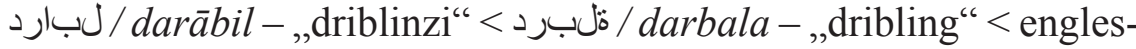
ki: dribbling, dribble.

S druge strane, za termin „bućica“, na primer, sreću se i drugi oblici koji nisu oblički uklopljeni u arapske paradigme za klase reči, već sa manje ili više uspeha prenose izvorni izgovor:

/ / زلبحد / dambilz - „bućica“ > engleski: dumbbells;

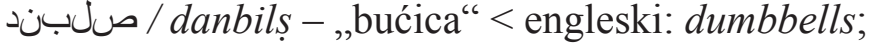

\section{Zaključak}

Fonološke pozajmljenice $\mathrm{u}$ analiziranom korpusu sportske terminologije čine gotovo jednu petinu zabeleženih termina (17.23\%) što znači da direktno pozajmljivanje predstavlja vrlo značajan izvor novih termina u savremenom standardnom arapskom jeziku. Najveći stepen pravilnosti, doslednosti i uklopljenosti u pravila arapskog jezika u korpusu arapske sportske terminologije zapaža se kod pozajmljenica koje su adaptirane prema arapskim oblicima reči. Međutim, njihov broj je i najmanji. Uz to, kako je istraživanje pokazalo, ni ti oblici nisu oslobođeni tereta dubletnosti.

Uopšteno posmatrano, prisustvo brojnih dubleta/multipleta predstavlja izraziti problem u arapskoj sportskoj terminologiji. Oni se javljaju kao posledica najmanje sedam faktora koji se neretko prepliću. To su: paralelna upotreba termina stranog i domaćeg porekla, upotreba različitih metoda za građenje termina, razlike u grafiji, upotreba adaptiranih pozajmljenica različitog porekla, oslanjanje na različiti izgovor prilikom adap- 
tacije pozajmljenica, upotreba različitih termina istog porekla i regionalna leksičko-terminološka varijantnost.

Samo po sebi, prisustvo terminoloških dubleta to jest terminološke sinonimije predstavlja neizbežnu i prirodnu jezičku pojavu, čak i u specijalnim jezicima gde se teži što većoj terminološkoj unifikaciji. Kod direktinih pozajmljenica $u$ arapskoj sportskoj terminologiji, međutim, primetno je prisustvo brojnih nedoslednosti na grafološkom, fonološkom i morfološkom planu adaptacije, a razlog za to je još davne 1960. godine naslutio ugledni francuski arabista V. Montej (Vincent Monteil) istakavši da se u arapskom ne upotrebljava nikakav sistem transkripcije stranih reči i imena i da se takve reči često ,izobličavaju i reprodukuju na više načina“ (Monteil, 1960: 43).

Ovo Montejovo zapažanje važi i danas. Naime, ne postoje nikakve pravopisne smernice niti pravila koja regulišu prenošenje stranih naziva, makar iz najrasprostranjenijih svetskih jezika, a tek se retki stručnjaci za arapski jezik pitaju da li adaptaciju stranih reči regulišu analogija ili ssvakodnevna upotreba. Činjenica da pozajmljenice potiču iz jezika sa nesrodnim pismima i fonološkim sistemima sama po sebi je već dovoljan izazov i bez pasivnog odnosa zvaničnih institucija prema tom vidu širenja opšteg leksikona i terminosistema. Jasno je da zvanične arapske jezičke institucije svojim ,nečinjenjem“ šalju nedvosmislenu poruku u vezi sa direktnim pozajmljivanjem i stavom koji prema njemu imaju. Ipak, neregulisanje pravopisnih postupaka kod prenošenja stranih naziva i svojevrsno ignorisanje prisustva pozajmljenica neće sprečiti pojavu direktnih pozajmljenica, niti odvratiti korisnike stručnih terminologija i opšteg leksikona da koriste i usvajaju pozajmljenice u budućnosti, kao što to nije postignuto ni u prošlosti. Naprotiv, to samo usložnjava problem i dovodi do pojave velikog broja proizvoljnih transkripcijskih rešenja koje opterećuju komunikaciju među stručnjacima i drugim korisnicima stručnih terminologija. Zvanične arapske jezičke institucije bi trebalo ozbiljno da se pozabave regulisanjem načina na koje se prenose konsonanti i vokali koji ne postoje u arapskom jeziku jer bi se time obezbedili stabilniji uslovi za dalji razvoj savremenog standardnog arapskog jezika.

\section{Literatura}

'ALAMĪ (al-), I. B. Ḥ. (2001). F̄̄ al-ta 'rīb. Al-Dār al-bayḍā': al-Nağāḥ al-ğadīd. 
ALI, A. S. M. (1987). A linguistic study of the development of scientific vocabulary in Standard Arabic. London/New York: Kegan Paul International.

BADAWI, E. et al. (2007). Modern Written Arabic: A Comprehensive Grammar. London/New York: Routledge.

BATESON, M. C. (1967). Arabic Language Handbook. Washington: Center for applied linguistics.

BEESTON, A. F. L. (1970). The Arabic Language Today. London: Hutchinson University Library.

ĐORĐEVIĆ, D. (2014). Sportska terminologija u standardnom arapskom jeziku (neobjavljena doktorska disertacija). Filološki fakultet, Beograd.

ELKHAFAIFI, H. M. (2002). Arabic language planning in the age of globalization. Language Problems and Language Planning, 26, 3, 253269.

HOLES, C. (2004). Modern Arabic: structures, functions, varieties. Washington: Georgetown University Press.

JANKOVIĆ, S. (1987). Arapski izgovor sa osnovama arapskog pisma. Sarajevo: Svjetlost.

KICO, M. (2003). Arapska jezikoslovna znanost: općelingvistička utemeljenja i specifična određenja. Sarajevo: Fakultet islamskih nauka.

MONTEIL, V. (1960). L'arabe moderne. Paris: C. Klincksieck.

MUFTIĆ, T. (1982). Arapsko pismo: razvoj, karakteristike, problematika. Sarajevo: Orijentalni institut u Sarajevu.

MUFTIĆ, T. (1998). Gramatika arapskoga jezika. Sarajevo: Ljiljan.

PARKINSON, D. (1991). Searching for modern fusha: real life formal Arabic. Al-'Arabiyya, 24, 31-64.

QINAI (al), J. B. S. (2000). Morphophonemics of loanwords in Arabic. Studies in the Linguistic Sciences, vol. 30, 2, 1-25.

ȘAYĀDI (al-), M. M. (1985). Al-Ta 'rīb wa tansīquhu fì al-wațan al- 'arabī. 4. izdanje. Bayrūt: Markaz dirāsāt al-waḥda al- 'arabiyya.

SCHMIDT, T. (2008). The Kicktionary: Combining corpus linguistics and lexical semantics for a multilingual footbal dictionary. In E. Lavric et al. (eds), The Linguistics of Football (pp. 11-21). Tübingen: Gunter Narr Verlag.

STETKEVYCH, J. (1970). The Modern Arabic Literary Language: Lexi- 
cal and Stylistic developments. Chicago/London: The University of Chicago Press.

VERSTEEGH, K. (2001). The Arabic Language. 2nd edition. Edinburgh: Edinburgh University Press.

Dragana Đorđević

\section{Summary}

\section{THE LOAN WORD ADAPTATION IN STANDARD ARABIC}

Loan words in Arabic represent one of the most important factors that enabled quick modernization of the Arabic language lexicon, as well as its expansion through introducing lexemes and terms that denote new concepts. The analysis of examples excerpted from a representative corpus of Arabic sports terminology points out problems that occur during the adaptation of loan words in Modern Standard Arabic in general. The accent of this paper is put on the adaptation of sounds without an equivalent in Arabic - both consonants and vocals, adaptation that is influenced by phonotactic rules of Arabic syllable, adaptation in accordance with Arabic word forms, as well as the role of phonetic assimilation, elision, epenthesis and prosthesis. Since the adaptation of loan words in Standard Arabic is not subject to any particular orthography norms or recommendations, this paper explores the lengths of differences in adaptation in the language use, the fact that contributes to the emergence of doublet terms and burdens the system of sports terminology, as well as other terminology systems and the general lexicon of Standard Arabic language. 